\title{
From the Blogosphere into Real Politics: \\ The Use of ICT by the Five Star Movement
}

\author{
Øystein Sæb $\varnothing^{1}$, Alessio Maria Braccini ${ }^{2}$ and Tommaso Federici ${ }^{2}$
}

\begin{abstract}
Research on ICT and the public discourse often focuses on how ICT can be used to increase citizen participation in political decision-making processes. The Italian Five Star Movement (5SM) represents a novel approach to using ICT to include citizens, and a big challenge for the traditional political actors. The 5SM was initiated outside the established political systems, with the use of Internet tools as cornerstones to promote political actions based on the directly expressed will of citizens. In this paper, based on an exploratory case study approach and informed by the introduction of E-Democracy models, we investigate the role of ICT in various phases of the 5SM, from its birth through the current stage. The focus here is on the transformation from a protest organisation outside the established political processes to being the second most voted party within the Italian parliament.
\end{abstract}

Keywords. E-Democracy, E-participation, Transparency, Online Communities

\section{Introduction}

In the last two decades, information and communication technologies (ICTs) have been used increasingly in the political field to involve citizens and to combat the decline in both interest and participation in democratic processes. The term E-Democracy is used to identify, in a very broad way, the different roles ICT can play in the relationships between citizens and central or local governments, and to stimulate citizens' involvement in political processes [1].

Many different examples of ICT involvement in the political field can be seen in practice. For example, some politicians make use of existing Internet platforms, like Facebook or Twitter, to involve citizens, to stimulate their participation and to win support in electoral processes. This is the case for the mayor of Bari (Italy), who uses his own Facebook profile to communicate with citizens, and who asked his councillors to do the same [2]. In other cases, organisations rather than individuals might act to support candidates in an election, as in the case

1 Dept. of Information Systems, University of Agder, Norway, oystein.sabo@uia.no

2 Dept. of Economics and Business, University of Tuscia, Italy \{abraccini,tfederici\}@unitus.it 
of www.mybarackobama.com, the blog created and launched by a non-profit organisation established to support Obama's electoral campaign in 2012 [3]. The European Commission has initiated a web space called "Your Voice" (http://ec.europa.eu/yourvoice/index.htm), which involves citizens in European political processes through consultations, debates and information sharing, similar to the US White House's platform called "We the People" (http://petitions.whitehouse.gov), which allows any citizen to create online petitions. The application of ICTs in these political processes was originally seen as opportunity to improve and modernise democratic systems by increasing transparency in politics and involving citizens in decision-making. So far, however, it seems that this goal has not been reached, at least not on a large scale [4].

The Italian "Movimento 5 Stelle" (Five Stars Movement; from now on 5SM) is an interesting example to analyze, due to the speed and scope of the achieved results, of an ICT application to political processes that started from people's actions first, outside the traditional political environment. The 5SM attracted activists from different areas of Italy. ICT played a relevant role in this process, as it provided the main communication channels for the 5SM (its headquarters is said to be its blog). In a short time, the movement entered the Italian political sphere, achieving significant results in elections, both at the local (municipalities, regions) and central (parliament) level. For all these reasons, the 5SM is a subject of great interest to many international observers [5], [6], [7] because it represents a big challenge to established political structures and traditional actors. One of the cornerstones of the 5SM is the use of simple Internet tools to allow citizens to express their will with regard to which political actions to promote. In this paper we aim to investigate the 5SM using an exploratory case study approach to investigate and reflect on the role of ICT in various phases of the 5SM, from its birth to the current stage, focusing on the transformation from a protest organisation outside the established political decision-making processes, to being the second most voted party in the Italian parliament.

\section{Theoretical Framework}

Ideas and ideals of democracy vary between societies, communities and even between stakeholders within one community. The idea of democracy leans fundamentally on effective communication and informed decisionmaking about public issues among citizens, politicians, officers and other stakeholders who may be affected by the decisions [8],[9]. Democratic models are idealised forms of democracy with a set of ideals about how democracy should take place, whereas E-Democracy models discuss how information and communication technologies may be used to shape democracies [10]. Many E-Democracy initiatives have remained rather unclear about the democratic model or specific goals, and mixed expectations among citizens and politicians 
with respect to E-Democracy have been reported [11]. As already mentioned, most E-Democracy projects are launched in order to involve more citizens in the existing political structure and decision-making processes [12]. Päivärinta and Sæbø [10] suggested an inclusive but simplified comparison of various E-Democracy models based on two fundamental dimensions: inclusion in decisions and control of the agenda [13]. Inclusion refers to the idea of whether or not all members of a society are able to participate in current debates and decision-making processes. Control of the agenda is related to the issue of who influences the political agenda in the first place. The resulting four stereotypical models are: Liberal, Deliberative, Partisan and Direct E-Democracy.

Liberal E-Democracy involves government-based initiatives and citizens' implicit connection to the decisionmaking process. The aim is to inform citizens (especially during elections) and gather informative feedback. Citizens participate less in the decision-making processes as such, since democracy is regarded as occurring after the citizens have been informed of the candidates' viewpoints before the elections, and about the decisions made in between elections. The main role of ICT is to improve the amount and quality of information exchange between government and citizens.

Deliberative E-Democracy connects citizens more explicitly to decision-making processes. Politicians and citizens share interest in dialogues and discourse leading to the formation of political opinions. Citizens have good reason to expect that their voices will be heard concerning a particular matter initiated by the government. In this model, ICT is developed to increase citizen participation and involvement in decision-making processes.

Partisan E-Democracy is characterised by citizen-initiated participation with no explicit connection to existing governmental or political decision-making processes. Citizens may influence the agenda for public discussion by their mere presence. In this model, ICT seeks to obtain visibility for alternative political expressions uninterrupted by the political elite.

Possibilities for Direct E-Democracy have been recently highlighted. Here, citizens online are directly affecting the decisions to be made. Citizens set the agenda both for public discussion and for decision-making. The presence of ICT is a crucial pre-condition for direct democracy to support coordination among decision makers.

Transparency is a key concept in the political scene, which has to be regarded as a multifold theme, with different and sometimes contradictory views. Transparency, with the meaning of richer and clearer information about government actions made available to every citizen, is generally seen as a way to improve the quality of a society (for a more profound discussion, see [14]). But, on the other hand, scholars referring to critical management studies see transparency as a fashion and are skeptical about its impact on government [15], even 
suggesting that greater transparency could result in reduced independence for organisations acting on the political scene [16]. Finally, when looking into organisational structures, building on Foucault [17], in terms of targets, performance tracking and exhibition of rule infringements, transparency is mostly seen as a devious but highly effective means for controlling the dependents by exerting a continuous tacit pressure on them. When ICTs support transparency in this sense, it begins to look something like an "Electronic Panopticon" [18].

\section{Research Design}

We apply an exploratory design to discuss the case of the Italian 5SM and investigate the use of ICT tools to involve citizens in political discourse [14]. The aim is to reflect on the role of ICT in the various phases of the transformation of a citizens' protest organisation into one of the largest parties in the Italian parliament. The unit of analysis for this case [19] is the 5SM. We chose this unit pertinent to the aim of the research because it is a novel case where the use of ICTs allowed individual citizens, who originally started a protest movement, to gather together, organise and participate in political life, achieving nation-relevant results.

The data for investigating the case are composed of a mix of direct observation and information available on websites, blogs, books, newspapers and magazines. Regarding the information available online, the sources most frequently used for the case study are the website of the 5SM itself (www.movimento5stelle.it), and the blog of Beppe Grillo (www.beppegrillo.it). Investigating the 5SM, we focus on the people, as well as the actions, ICT tools and organisational settings that were used to participate in traditional political processes. The result of the exploratory case will be the formulation of propositions to be tested and investigated in future research projects.

\section{The 5SM Case: the Primordial Soup}

The 5SM is an Italian political movement recently founded by a former prominent Italian comedian (Beppe Grillo), and by an Italian entrepreneur (Gianroberto Casaleggio). The 5SM was founded after a political action stimulated by Grillo himself. This movement sharply distinguishes itself from traditional parties, claiming to be more open, transparent and representative. The 5SM's activists depict the 5SM as a 'non association' with a 'non statute' [20], having its headquarters on the web. Thanks to his profession as a comedian, Grillo has been widely popular in Italy since the 80s. He also became known for his strong critical stances against the institutional and political establishment. His critical thoughts have been diffused through his personal blog since 2005. The blog allows visitors to post comments and to share its content on the most popular social networking platforms. The 
popularity of Grillo on the one hand, and of his blog on the other, have reinforced each other through the years. The blog became so popular that Grillo was listed as the seventh most influential person on the web by the Forbes magazine in 2009 [21].

\section{Initial Line Up: the Partisan Phase}

Following the popularity of Grillo and of his blog, an increasing number of citizens started to follow him and his ideas, and to discuss politics. However, it was only in 2008 that the blog (i.e., Grillo) and its followers explicitly declared that they were politically active. Participation on the blog increased and soon it could not support the large group of followers. People wanted to be active not only on the blog, but also in their territories, discussing real social and political problems that were really close to them.

In order to organise the actions of individual groups in the territories and to coordinate their activities, Grillo proposed adopting Meetup (www.meetup.com), a social networking platform created by a North American company, which had already been used by Howard Dean to successfully run against John Kerry in the 2003 US primaries. The platform was adopted with the original spirit of getting together to formulate opinions and proposals on topics of civic relevance, and to improve the world, starting from the single territories where each group was active. Initially, 40 groups were created on Meetup, but this number grew to 472 by 2012 [22], and to 1,250 with 109,999 members in 1,038 cities from 20 different countries as of this writing (an updated list of the groups is available at: http://movimento-5-stelle.meetup.com).

At this stage, Grillo's groups were not connected with the traditional political representation processes. The groups were active in the territories and at the national level just to promote discourse on topics of civic interest, which was by that time separate from the political discourse carried out at the institutional level.

\section{Stepping into Political Processes: Forms of Direct and Deliberative Democracy}

At the end of 2007, Grillo started to provide open and self-organised spaces to the local Meetup groups during his performances around Italy. The aim was to further disseminate their activities, and those of their attendees, and to attract more people. Later the same year, a nationwide event called V-Day was launched. Although the 5SM was not yet established as a movement at that time, this event was the first when a mass of activists mobilised by Grillo's blog and by the local groups had entered into the traditional institutional process - though in a traditional (non ICT-based) way. During this event, signatures were collected from citizens to promote a law of popular initiative to modify regulations for candidacy to the parliament. A similar event was also promoted 
the following year. The political action of people involved in the Meetup groups started to enter institutional political processes in 2008. With the intent to participate in administrative elections, some of the Meetup groups started local civic lists following a set of common rules that Grillo had established for them. At this stage, a specific area of Grillo's blog was dedicated to these lists. Through this area, individual citizens could participate in the political life of their region or territory.

The 5SM was formally founded as an association in 2009 , with the anticipated intention of promoting and coordinating the activities of the civic lists, and of running for the parliamentary elections. To do so, Grillo registered the 5SM trademark. The statute of the 5SM (art. 3) [20] limits all rights to the use of this trademark to Grillo himself. The statute also states that the Internet plays a crucial role for the 5SM, and that it is used to let citizens enter into the movement for consulting, deliberating, decision-making and electing purposes. Furthermore, the statute of the movement recognises that all Internet subscribers play a role in governance that is normally assigned to only a few people in a traditional party. The headquarters of the 5SM is the blog itself, in a special section of Grillo's blog (http://www.beppegrillo.it/movimento), which remains significant in this new phase.

After this phase, the blog was often used as a discussion forum (contents are readable by anyone, but contributions are restricted to citizens members of the 5SM) in the agenda-setting process. The blog was also the location in which direct democracy processes took place. This was the case, for example, for the online vote to choose the candidates that had to be in the 5SM lists for the parliamentary elections. In this regard, the statute specifies that the online voting system works according to rules that might be better decided on each occasion, and adjusted according to each experience. Grillo diffused generic rules on his blog before the online voting for selecting members to lists for parliamentary elections. The same system, but with a more deliberative nuance than a direct democracy one, was also used during the election of the president of the Republic in 2013, when, through an online vote, citizens nominated the candidates for the Italian Republic presidency that 5SM parliamentarians had to support in the election process.

In February 2013, the 5SM succeeded in gaining seats in the two chambers after the parliamentary elections, and a code of conduct was disseminated for its parliamentarians. Amongst other things, the code explicitly states that law proposals can be promoted by citizens through an online voting system. Each citizen's proposal that gets at least $20 \%$ of the online votes will be presented by the 5SM parliamentarians in the parliament. Citizens shall also be consulted when parliamentarians have to be excluded from the 5SM group. The 5SM parliamentarian group can vote for the exclusion of a member in case of a violation of the code of conduct, but such exclusion 
must be confirmed by the online votes of the followers.

The 5SM statute also states that parliamentarians elected to the 5SM lists shall form a 5SM group in each of the two chambers of the Italian parliament. Each group is entitled by law to receive funds from the parliament for communication and study tasks. The statute states that two communication groups (one for each chamber) will be formed, and Grillo will appoint the staff of these groups. The funds for communication and study activities received by the Italian parliament shall be devoted to supporting this communication staff, and candidates to the parliament must confirm this by signing a written agreement before participating in the elections.

Finally, other examples of ICT use by the 5SM involve streaming technology to broadcast their meetings on the Internet, or meetings with other political forces (i.e., for example, the meeting during the consultation process that led to the formation of the current Italian government). The 5SM parliamentarians also use their own Facebook and Twitter channels to disseminate their activities. The communication groups in the parliament also use a YouTube channel and the blog to periodically inform the citizens about the activities performed by 5SM parliamentarians.

Notwithstanding its strong profession of transparency and direct open participation, the 5SM is also subject to many severe criticisms, about just these issues. Some examples in this regard, include:

- A huge number of critical posts removed from the 5SM website. The criteria or motivations for such removals were not disclosed, so an external website (http://nocensura.eusoft.net/) was created by a private blogger to track and enumerate all the posts banned from the 5SM website;

- Decisions to banish some 5SM activists, autonomously made by Grillo. Since Grillo is the owner of the trademark and Casaleggio maintains the website, they can proceed by warning an activist through a formal legal notice not to use the 5SM mark anymore, and by removing his/her account;

- Recurrent blackmails by Grillo, threatening retirement of the blog and withdrawal of the mark, in order to prevent followers from voting on possible coalitions with other parties;

- Often incomplete streaming of the internal meetings, or not streaming them at all.

\section{Discussion}

The 5SM case exemplifies the use of ICT for a movement that started as a partisan E-Democracy initiative without any direct influence on formal decision-making processes. Differently from most E-Democracy initiatives promoted by institutions to involve more citizens in the political processes, the 5SM originated outside 
the traditional systems and became a political force through the will of the citizens. In other words, it was citizen-driven rather than party-driven.

In its move towards a position with more explicit political influence, the 5SM used ICT to establish direct democracy processes within the movement's internal decision-making processes. Currently, the 5SM has gained formal decision-making power through its seats in the national parliament. The case is interesting from a research point of view for several reasons. The shift from a movement that was outside the political system to a movement with seats in parliament, and the critical importance of ICT in order for the movement to exist are quite extraordinary and represent something new within the research field.

The use of ICT proved crucial for the development of the 5SM: to acquire attention, to arrange for the development of the movement's politics and to coordinate its activities. But, despite the importance of the technology itself, the 5SM exemplifies the importance of context and structure to understand the use of the ITapplication (such as the blog and the Meetup system). Grillo had already gained popularity and established a role as an opponent of the public elite before initiating his blog. He spent time and effort to increase his impact and the number of his followers. Thus, when the economic crisis really hit Italy (and Europe), Grillo already had his speaker's platform to criticise the established elite, holding them responsible for the lack of political accountability

The 5SM makes use of ICT for internal direct democratic processes, allowing the (registered) members to participate in decision-making, including decisions on how representatives should vote in parliament. Simultaneously, the 5SM challenges some democratic ideals concerning both internal and external processes, and there could be some concerns regarding how transparent the use of ICT actually is. Internally, communication is to be conducted through the movement's blog, which is highly influenced by Grillo himself. The two founders privately own the 5SM trademark and website. Consequently, they could control (and monitor) online activities if they wish, possibly applying internal transparency in the sense evoked by critical scholars; that is, to exert tacit pressure on members. This point should be further investigated.

Only scattered information is available on issues such as the possibilities for censoring, procedures for complaints and the delineation between the movement's 'official' information and Grillo's private communications (if such a delineation exists). Somewhat related to this, is the only-partial availability of streaming from internal meetings. Such external opacity on internal events and behaviours could possibly be associated, according with critical theories, with the preservation of independence by organisation acting on the political scene. 
Externally, the movement's representatives have not participated in any public debate, and are not allowed to negotiate with representatives from other parties, since the 5SM politics are to be decided by the members. More research is needed to explore the duality of highlighting internal democratic processes (despite some challenges) while ignoring participation in the public discourse and negotiations within the established political system. Also, the capacity of ICT to actually warrant that transparency and openness exist in all circumstances, to correspond to what promised in advance, should be further investigated.

The 5SM is still in its initial phase, and more research is needed to explore the consequences of its appearance in the established political system, as well as the critical importance of ICT. Future research should look into the implicitly democratic influence the use of ICT may have. For instance, ICT with the set of norms and regulations it has applied may foster transparency by allowing everyone to access information, but, on the other hand, the adopted rules may also withhold information from the citizens (and members) by hiding information regarding who is in charge of making a decision, what the routines are for censoring and monitoring, and by automatically performing processes and routines that may influence decisions to be made.

\section{Conclusions and limitations}

This paper analyses, through an exploratory case study, the 5SM case with respect to the role that ICT played in its transformation from a protest movement born outside the political system to a relevant political force with representatives in the Italian parliament.

The case points out the need to further investigate issues related to the use of ICT, not only focusing on the technology itself, but also on the surrounding organisational environment (i.e., roles and rights, regulations and norms) that shapes the way people use the technology to participate in democratic processes. The case also raises questions on the challenges a political force that heavily bases its political processes on the Internet poses to those more traditional ones that do not.

The 5SM case is an on-going phenomenon, and some of the issues discussed in this paper are also elements of discussion within the movement itself. Future research will be addressed to investigate the issues identified and discussed here.

\section{References}

[1] Rahman, M.M., Ahsan Rajoin, S.A.: An Effective Framework for Implementing Electronic Governance in Developing 
Countries: Bangladesh Perspective. International Journal of Computer and Information Technology, 3(1), pp. 360-365 (2012)

[2] Braccini, A.M., Federici, T.: New Internet-based Relationships Between Citizens and Governments in the Public Space: Challenges for an Integrated System Design. In: Baskerville, R., De Marco, M., Spagnoletti, P. (eds.) Designing Organizational Systems. An Interdisciplinary Discourse, pp. 157-180. Springer, Heidelberg (2013)

[3] Fondazione <ahref: I Media Civici in Ambito Parlamentare. Servizio Informatica del Senato della Repubblica, Roma (2013)

[4] Chadwick, A.: Web 2.0: New Challenges for the Study of E-Democracy in an Era of Informational Exuberance. I/S: A Journal of Law and Policy for the Information Society, 5, (2008)

[5] The Economist: The Five Star Movement - The Crickets Come Out. March 2nd (2013)

[6] Fleischhauer, J.: Green Fascism: Beppe Grillo is the Most Dangerous Man in Europe, Der Spiegel online International, March 15th (2013)

[7] Lewis, J., Aristea, J.: Dangerous Times: Crypto-Fascism in Italy, Hungary, Greece, Albania. American Thinker, March $23^{\text {rd }}(2013)$

[8] Habermas, J.: Between Facts and Norms: Contributions to a Discourse Theory of Law and Democracy. MIT Press, Cambridge, USA (1996)

[9] van Dijk, J.: Models of Democracy and Concepts of Communication. In: Hacker, K.L., van Dijk, J. (eds.) Digital Democracy, Issues of Theory and Practice, pp.30-53. Sage Publishing, London (2000)

[10] Päivärinta, T., Sæbø, Ø.: Models of E-Democracy. Communications of the Association for Information Systems, 17(1), pp. 818-840 (2006)

[11] Rose, J., Sæbø, Ø.: Democracy Squared: Designing on-line Political Communities to Accommodate Conflicting Interests. Scandinavian Journal of Information Systems, 17 (2), pp. 133-168 (2005)

[12] Medaglia, R.: eParticipation Research: Moving Characterization Forward (2006-2011). Government Information Quarterly, 29(3),pp. 346-360 (2012)

[13] Dahl, R.A.: Democracy and its Critics. Yale University Press, New Haven, CT, USA (1989)

[14] Federici, T., Braccini, A. M. How Internet is Upsetting the Communication Between Organizations and their Stakeholders: A Tentative Research Agenda. In M. De Marco, D. Te'eni, V. Albano, S. Za (eds.) Information Systems: a Crossroad for Organization, Management, Accounting and Engineering, pp. 377-385, Physica-Verlag, Berlin Heidelberg (2012)

[15] Tadajewski, M., Maclaren, P., Parsons, E., Parker, M. Key Concepts in Critical Management Studies, pp. 9-10. Sage Publishing, CA, USA (2011)

[16] Bertelli, A. M. Credible Governance? Transparency, Political Control, the Personal Vote and British Quangos. Political Studies, 56(4), pp. 807-829 (2008)

[17] Foucault, M. The Eye of Power. In C. Gordon (ed.) Power/Knowledge, Selected Interviews and Other Writings, 1972- 
1977, pp. 146-165, Harvester Press, Brighton, UK(1980)

[18] Glenday, D. Power, compliance, resistance and creativity: Power and the differential experience of loose time in large organisations. New Technology, Work and Employment, 26(1), pp. 29-38 (2011)

[19] Yin, R.K.: Case Study Research: Design and Methods. Sage Publishing, CA, USA (1994)

[20] Movimento 5 Stelle: Non Statuto, www.beppegrillo.it/iniziative/movimentocinquestelle/ Regolamento-Movimento-5-Stelle.pdf

[21] Ewalt, D.M.: The Web Celeb 25, http://www.forbes.com/2009/01/29/web-celebrities-internet-technologywebceleb09_0129_top_slide_8.html

[22] Carbonaro, M.: Grillo Vale Uno. Iacobelli Editore, Rome (2013) 